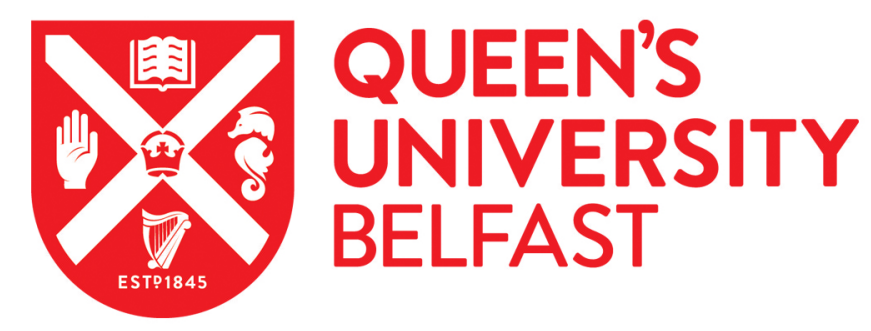

\title{
A translational case study of empowerment into practice: a realist evaluation of a member-led dementia empowerment service
}

McConnell, T., Best, P., Sturm, T., Stevenson, M., Donnelly, M., Taylor, B., \& McCorry, N. (2020). A translational case study of empowerment into practice: a realist evaluation of a member-led dementia empowerment service. Dementia:The International Journal of Social Research and Practice, 19(6), 1974-1996. https://doi.org/10.1177/1471301218814393

Published in:

Dementia:The International Journal of Social Research and Practice

Document Version:

Peer reviewed version

Queen's University Belfast - Research Portal:

Link to publication record in Queen's University Belfast Research Portal

Publisher rights

Copyright 2018 SAGE. This work is made available online in accordance with the publisher's policies. Please refer to any applicable terms of use of the publisher.

\section{General rights}

Copyright for the publications made accessible via the Queen's University Belfast Research Portal is retained by the author(s) and / or other copyright owners and it is a condition of accessing these publications that users recognise and abide by the legal requirements associated with these rights.

Take down policy

The Research Portal is Queen's institutional repository that provides access to Queen's research output. Every effort has been made to ensure that content in the Research Portal does not infringe any person's rights, or applicable UK laws. If you discover content in the Research Portal that you believe breaches copyright or violates any law, please contact openaccess@qub.ac.uk. 


\title{
A translational case study of empowerment into practice: a realist evaluation of a member-led dementia empowerment service
}

Dr Tracey McConnell School of Social Science, Education and Social Work, Queen's University Belfast. t.mcconnell@qub.ac.uk. *Corresponding author.

Dr Paul Best, School of Social Science, Education and Social Work, Queen's University Belfast, Northern Ireland

Dr Tristan Sturm, School of Natural and Built Environment, Queen's University Belfast, Northern Ireland

Mabel Stevenson, School of Social Science, Education and Social Work, Queen's University Belfast, Northern Ireland

Prof. Michael Donnelly, School of Medicine, Dentistry and Biomedical Sciences, Queen's University Belfast, Northern Ireland

Prof. Brian J Taylor, School of Applied Social and Policy Sciences, Ulster University, Northern Ireland

Dr Noleen McCorry, School of Medicine, Dentistry and Biomedical Sciences, Queen's University Belfast, Northern Ireland

\begin{abstract}
Involving people with dementia in decision-making is widely accepted as a means of empowering them to lead more independent lives and have more meaningful roles in shaping their care. However, there is a need to conduct rigorous evaluations of empowerment-driven services and policies in order to develop a deeper understanding about how to optimise successful implementation. This paper presents the results of an evaluation of Dementia $\mathrm{NI}$, an organisation initiated and led by people with dementia. We used a realist evaluation approach that comprised interviews with 15 people with dementia, three staff and two board members, ethnographic observations, along with documentary analysis to identify 'what works, for whom, under what circumstances'. Analysis used realist logic to build up contextmechanism-outcome configurations (CMOcs). The Dementia $\mathrm{NI}$ service model of empowerment revolved around the formation and maintenance of social groups of people with dementia. Facilitators, recruited and selected by people with dementia, supported six groups, consisting of one to four members with mild to moderate cognitive impairment. Facilitators helped expand empowerment groups, facilitate decision-making, awareness raising and consultation opportunities with group members. The 'Empowerment Groups' appeared to lead to the development of a shared social identity and a sense of collective strength as indicated by interview and observational data demonstrating an activist mentality among group members to challenge the stigma surrounding dementia. Group members also reported improved quality of life. Widespread implementation of the empowerment model has the potential to lead to reduced stigma and greater social inclusion, increased involvement of people with dementia as active co-producers of policy and service development, better services and support. This case study of Dementia NI illustrates that there are boundaries and challenges to empowerment in terms of requiring additional support from staff without dementia. However, despite these challenges, empowerment-driven organisations can and should be committed to involving members in lead roles and key decision-making.
\end{abstract}


Keywords: Realist evaluation, empowerment, dementia, member-led, translational, social power, facilitator, awareness raising, consultation, shared decision making

\section{Introduction}

Estimates suggest that approximately 46.8 million people worldwide have dementia, with numbers projected to double over the next 20 years (Prince et al., 2015). There is increasing worldwide recognition that services for people with dementia require improvement as evidenced by the creation of a World Dementia Council, a World Dementia Envoy appointment after the G8 dementia summit held in London in 2013, and a Ministerial Conference on dementia in 2015 hosted by the World Health Organisation (WHO) (Bartlett, 2016).

At the national UK scale, Living Well with Dementia (Department of Health and Social Care [DoHSC], 2009)—part of the UK National Dementia Strategy, and the subsequent Prime Minister's Challenge on Dementia (DoHSC, 2012) outline various UK government goals but arguably lack substance in terms of giving voice and leadership opportunities for people with dementia.

Although involving people with dementia in decision making is widely accepted as a means of preserving autonomy, rights and personhood, we still lack good evidence about the most effective, person-centred ways in which to achieve meaningful involvement, particularly involvement that is initiated and led by people with dementia and that relates to decisions regarding independent living (Bartlett, 2016).

A recent review (Miller, Whitlatch \& Lyons, 2014) found that while service users with dementia wanted to participate in decisions about, for example, their treatment and care, the actual level of involvement was limited and declined considerably as dementia progressed beyond mild cognitive impairment. Therefore, it is still unclear if empowerment initiatives can actually be translated into practice in terms of empowering people with dementia to influence relevant policies and services.

\section{Dementia NI}

These kinds of translational challenges, issues, and problems are addressed by Dementia NI (DNI) - an organisation initiated in 2015 which is led by people with dementia. Inspiration for DNI was taken from the UK Dementia Engagement \& Empowerment Project (DEEP) which defines its practices as "engaging and empowering people living with dementia to influence services and policies that affect their lives." The ethos of the organisation centres on empowerment and enablement. The intended outcomes of the organisation include the improvement of quality of life for members through enhancing social activity and providing opportunities to make a difference to the lives of people with dementia. DNI seeks to achieve these goals by developing members' skills in relation to consulting on policy and healthcare documents relevant to dementia care, along with media and public speaking to raise awareness and reduce the stigma surrounding dementia.

A search of the empowerment literature helped identify potential theories in relation to how and why such empowerment initiatives may translate empowerment of people with dementia into practice. A common theme related to empowerment as a process by which individuals, organisations and communities gain control over their lives and are enabled to actively participate in improving their own situation (Raeymaeckers \& Dierckx, 2013). Empowerment was therefore conceptualised as a multilevel concept (Rappaport, 1987). At a micro level (individual level), empowerment involved gaining personal control and critical awareness of one's socio-political situation. At an organisational level empowerment involved being consulted, heard, and actively involved in decision making. At a societal level, empowerment involved enhancing quality of life, increasing autonomy and being supported to overcome social exclusion (Perkins \& Zimmerman, 1995; Zimmerman 1995). 
The implicit programme theory is that Dementia NI supports the empowerment of people with dementia through a range of activities, by developing autonomy and leadership, improving inclusion, and changing perceptions of dementia, in a region where people with dementia were lacking a local voice.

However, these change processes have not been systematically evaluated in the context of member-led empowerment services. Therefore, we set out to investigate this initial programme theory to deepen our understanding of how empowerment initiatives work, under what circumstances and for whom in order to provide a new model for informing similar initiatives; thereby advancing the opportunity for meaningful empowerment of people with dementia.

\section{Methods}

This study was a realist evaluation using multiple methods, including interviews, ethnographic observations, and documentary analysis. The main goal is to undercover 'what works, for whom, under what circumstances, and how' (Pawson \& Tilley, 2004), as understanding these processes is important for informing policy and practice in terms of what helps or hinders successful and sustainable implementation of empowerment initiatives for people with dementia across different settings. Cheyne, Abhyankar and McCourt (2013, p. 1112) explains, "The realist approach makes explicit the principle that it is not programmes (i.e. the intervention or service) in them-selves that work, but rather it is the opportunities/ideas they offer people to make them work." It recognises the powerful role of context in the lives of people with disability. For example, it is not possible to have a full understanding of outcomes (e.g. empowerment, independent living) without an understanding of context. This focus also provides greater insight about potential transferability, thereby increasing external validity (Marchal, Dedzo \& Kegels, 2010).

Realistic evaluation is well-established within the health and social care service delivery field (Greenhalgh et al., 2009) and has in this case enabled a flexible approach to investigating the realist research question Within the realist method, quantitative and qualitative data collection measures are utilised, including interviews and observations conducted across different time points, thereby allowing triangulation of findings to ensure accuracy and reliability.

A core principle of realist evaluation is that programmes work differently depending on the context into which they are introduced. For example, if the context is right, it will trigger the mechanisms required for success, if not these mechanisms will remain dormant. In realist evaluation, mechanisms refer to service users' mental processes (cognition and affect): the unseen forces of reasoning in response to resources offered by an intervention that leads to behaviour change (observable/measurable outcomes).

\section{Initial formulation of programme theory}

We searched the empowerment literature, DNI's website, along with the organisations aims/objectives and newsletters. We also conducted two informal interviews with DNI staff and members, where we started to explore what their theories were in relation to how and why DNI may empower people living with dementia (Table 1)

Table 1. Initial hypotheses gleaned from the literature, organisational specific documentation, and informal interviews with Dementia NI staff and members

Empowerment may be translated into practice when: 
People with dementia have more autonomy and feel their opinions are being heard at organisational, societal and political levels

People with dementia are enabled to actively participate in improving social inclusion and reducing stigma for people with dementia

Leadership opportunities are facilitated within empowerment organisations

Leading to our initial programme theory that - Dementia NI supports the empowerment of people with dementia through a range of activities, by developing autonomy and leadership, improving inclusion, and changing perceptions of dementia, in a region where people with dementia were lacking a local voice

\section{Data collection}

As in all realist evaluations, our data collection was theory driven. We conducted the study through phases of theory generation, testing and refining, beginning with specifying our initial programme theory. The initial programme theory provided a starting point for guiding the data collection and analytical approach. Following analysis of data from round 1, we developed an initial set of programme theories using CMO configurations. These theories were then tested and refined during round 2 and 3 . Table 2 . outlines the participants and type of data collected.

Data collection involved three rounds using the following methods:

\section{Observations}

Our observational engagement with DNI took place in Empowerment Group meetings, awareness raising events, and in attendance of board meetings. Observations occurred over a 6-month period for approximately 4 hours per observation, once or twice week depending on the researcher's schedule and availability of individuals at DNI. During observations, the researcher jotted down notes in a notebook and took a "participate to write role" that used insights offered by Emerson, Fretz and Shaw (2011). However, the researcher was attentive to situational appropriateness, and did not take notes when doing so would be viewed as insensitive. On such occasions, notes were jotted at a later, more appropriate time. The jottings made during the observations were expanded into fuller field notes after each observation session was finished.

Good ethical practice required a reorientation toward sensitive, flexible, and self-reflexive emotional landscapes, with careful consideration of positionality and the negotiation of difference and power concerning ability and researcher, respectively (Laurier \& Parr, 2000). Researchers were careful not to biomedicalize the member participants, treating them instead as co-producers of knowledge, encouraging them to tell stories and create the categories for analysis (O'Connor, Phinney \& Hulko, 2010; Varley, 2008). The observer effect/impact was negotiated through limited interaction in observational settings and friendly and caring introductions in each observational event. We also conducted concluding interviews with the facilitators of the empowerment groups to ascertain fidelity and any changes in behaviour among members with researchers present.

\section{Semi-structured interviews}


The first round of face-to-face, individual interviews were conducted using an exploratory interview topic guide based on initial programme theories. Round 2 and 3 focused on testing and refining evolving theories developed from round 1 data analysis. Round 2 and 3 interviews used theoretical sampling, which involved selecting further participants to help test previous explanations in relation to how and why the Dementia $\mathrm{NI}$ service model of empowerment led to observed outcomes. While a topic guide was used, the interviews were semi-structured to allow flexibility, the generation of new ideas, and in recognition that people with dementia require additional time to process information. Interviews were conducted by the qualitative lead (TS) and a research assistant (MS) with prior experience and formal training in ethnographic observation, interviews, and other qualitative data collection methods. Interviews were audio recorded and transcribed for analysis. Each interview lasted approximately 40-60 minutes, and took place in a private space convenient to participants.

\section{Documentary analysis}

A range of $\mathrm{DNI}$ organisational specific documents were accessed, including Criteria for referrals to DNI Membership Applications, Group Agreement for New Members, Group Meeting Format, Group Meeting Preparation, DNI Visitor Request Forms, Principles on Working with DNI Members, and a 'Closing the Loop' document, which is a feedback tool completed by visitors, such as public health charities, healthcare service providers, and policy makers, outlining how much they, or their organisation were able to implement changes based on the requests and opinions of members. These bespoke documents, developed by both DNI staff and members, helped contextualise and supplement other sources of data.

Table 2. Data Collection

Rounds of Data Collection

Round 1

Round 2

Round 3

Observations

DNI Empowerment Group meetings

Public events 1

DNI Board meetings

Total observations per round

Interviews

DNI members (people with dementia)

DNI staff
3

5

7

1
1

1 
DNI Board members

Total interviews per round

Interview total overall

Documents total
1

5

20

8

\section{Sample}

All current users ( $n=15)$, staff $(n=3)$ and board members $(n=5)$ of DNI were contacted via email by TS and MS in order to organize semi-structured interviews and observations. Written informed consent was sought. In keeping with the principles of empowerment, choice, and freedom, the five stages of Dewing's (2007) process consent model were applied - (1) background and preparation; (2) establishing the basis for capacity; (3) initial consent; (4) ongoing consent monitoring; and (5) feedback and support. This method has been developed exclusively from work with individuals with dementia and across a number of settings (Donnelly, 2004). These five stages were applied in this project as follows: (1) initial preparation work observing Dementia NI members in their empowerment group environment, interacting with members, and discussions with staff who had developed insights on a more personal level with members. (2) This work enabled the researchers to gain an understanding of the abilities and interests of members, and also to establish a basis for capacity within the group context. Gathering of medical evidence to establish capacity was considered unnecessarily invasive given the nature of the organisation, including their membership guidance. (3) Initial consent was obtained in two steps. First by submitting a request form to the group with information on the research allowing members to decide whether they wanted to be involved. Written consent was then obtained on the day of the research exercise after verbally and visually (paper and overhead) recapping the nature of their role in the research process. (4) Consent was monitored throughout by both the researchers and the Dementia NI group facilitator (who was familiar with members) paying attention to any verbal or behavioural cues indicating that a member did not understand the activity. (5) Ongoing support was provided by Dementia NI staff following the activity. A feedback form using the member's own template was subsequently submitted to the group by the research team.

\section{Analysis}

Interview, observational, and documentary data were thematically analysed by MS, TS and TM. Analysis began with reading and re-reading transcripts, field notes, and DNI documents before using thematic analysis to code the interview, observational, and documentary data (Fereday \& Muir-Cochrane, 2006) using NVIVO software. Patterns and themes were then identified to help develop CMO configurations (the relationships between factors that explained outcomes of the service, and the conditions in which they operated) - which were then discussed and refined by the research team. Data analysis followed an iterative approach whereby developing theories were debated prior to drafting CMO configurations, and then refined through a number of subsequent interviews, observations and feedback sessions with members. The findings section presents the agreed CMO configurations resulting from this iterative process, with quotes reflecting how we developed our theories in relation to what works, for whom, in what circumstances, when implementing empowerment initiatives for people with dementia. Table 3 provides a summary of CMO configurations.

\section{Ethics}


Ethical approval was granted from the Queen's University Belfast School of Social Sciences, Education and Social Work's Research Ethics Committee (Reference: SREC006/2016-17)

Ethical issues, and additional safeguards when involving people with dementia as research participants were recognised and addressed as follows:

(1) Capacity to give informed consent was addressed in accordance with Dewing's (2007) process consent model (as described in the Sample section) (2) Avoiding tokenism was addressed by ensuring member involvement was fitting with the remit, abilities and interests of the group (3) Recognition of power dynamics was addressed by ongoing reflection in relation to the interpersonal skills of the researcher, avoiding leading questions, and ensuring interview and observation quotes were the words of the person with dementia rather than those of the researcher (Stevenson \& Taylor, 2017).

To maintain confidentiality no names or identifying information is included in participant quotes.

\section{Findings}

Analysis revealed that DNI operates using three distinct, but interdependent activities - which can be derived from the organisational goals, and are reflected in the initial programme theory. These activities were classified early in the analysis cycle as: empowerment groups, awareness raising, and consultation.

Findings are presented as Context-Mechanism-Outcome configurations (CMOc), organised under the intervention strategies utilised by DNI. The final refined programme theory acknowledges the 'gestalt' nature of these strategies in contributing to the outcomes of the organisation.

Table 3. Context-Mechanism-Outcome configurations (CMOcs)

\begin{tabular}{|c|c|c|}
\hline Context & Mechanisms & Intended outcomes \\
\hline \multicolumn{3}{|l|}{ Empowerment Groups } \\
\hline $\begin{array}{l}\text { Enabling } \\
\text { - Experienced and } \\
\text { effective facilitators } \\
\text { - Size of group is } \\
\text { sufficient to allow for } \\
\text { discussion and } \\
\text { comparison }\end{array}$ & $\begin{array}{l}\text { Opportunities in which people with } \\
\text { dementia encouraged and } \\
\text { facilitated to use existing skills and } \\
\text { learn new skills } \\
\text { Encouraged to make decisions } \\
\text { around improving services and } \\
\text { support for people with dementia } \\
\text { Safe space for peer support where } \\
\text { people with dementia can share } \\
\text { experiences and learn more about } \\
\text { dementia }\end{array}$ & $\begin{array}{l}\text { Improve quality of life for members } \\
\text { - Enhanced peer networks } \\
\text { and social activity } \\
\text { Including observed outcomes that } \\
\text { help explain how intervention } \\
\text { leads to intended outcomes } \\
\text { - Increased confidence and } \\
\text { - Self-esteem } \\
\text { Sense of control over one's } \\
\text { - Kept members' minds } \\
\text { - active. } \\
\text { More openness around } \\
\text { - diagnosis of } \\
\text { dementia }\end{array}$ \\
\hline
\end{tabular}




\begin{tabular}{|c|c|c|}
\hline & $\begin{array}{l}\text { Trusting relationship between } \\
\text { group facilitator and members so } \\
\text { members motivated to take part }\end{array}$ & $\begin{array}{ll}\text { - } & \text { Improved relationships } \\
& \text { with family and friends } \\
\text { - } & \text { Reduced isolation }\end{array}$ \\
\hline $\begin{array}{l}\text { Disabling } \\
\text { - Stigma surrounding } \\
\text { dementia, especially in } \\
\text { rural areas where the } \\
\text { illness still very much a } \\
\text { 'taboo' subject }\end{array}$ & $\begin{array}{l}\text { People with dementia reluctant to } \\
\text { join empowerment group }\end{array}$ & $\begin{array}{l}\text { Size of group not sufficient to allow } \\
\text { for discussion and comparison }\end{array}$ \\
\hline \multicolumn{3}{|c|}{ Awareness Raising Activities } \\
\hline $\begin{array}{l}\text { Organisational and staff } \\
\text { support } \\
\text { Resources and expertise } \\
\text { for media training and } \\
\text { other awareness raising } \\
\text { activities } \\
\text { Positive feedback from } \\
\text { consultation exercises }\end{array}$ & $\begin{array}{l}\text { Organisation and group facilitators } \\
\text { provided members with the tools } \\
\text { required for raising public } \\
\text { awareness and educating the } \\
\text { public on dementia. This } \\
\text { generated an 'activist' mentality } \\
\text { among members, where they drew } \\
\text { on their new found confidence, } \\
\text { collective strength, and were } \\
\text { motivated and driven to reduce the } \\
\text { stigma surrounding dementia, } \\
\text { along with highlighting the need for } \\
\text { improving services }\end{array}$ & $\begin{array}{l}\text { Satisfaction from making a } \\
\text { difference to the lives of people } \\
\text { with dementia } \\
\text { Greater opportunity for civic } \\
\text { contribution and political influence } \\
\text { at local and national level } \\
\text { Improved public awareness and } \\
\text { understanding of dementia } \\
\text { resulting in reduced stigma and } \\
\text { greater social inclusion of people } \\
\text { with dementia }\end{array}$ \\
\hline \multicolumn{3}{|l|}{ Consultation } \\
\hline $\begin{array}{l}\text { Empowerment groups } \\
\text { provide a forum through } \\
\text { which people with } \\
\text { dementia can be } \\
\text { consulted and involved in } \\
\text { decisions affecting their }\end{array}$ & $\begin{array}{l}\text { Enables members to have a voice, } \\
\text { and builds their confidence to } \\
\text { challenge those with decision } \\
\text { making power to listen and act on } \\
\text { the advice and guidance provided } \\
\text { by those actually living with } \\
\text { dementia }\end{array}$ & $\begin{array}{l}\text { Better informed policy makers and } \\
\text { service providers who recognise } \\
\text { the needs and aspirations of } \\
\text { people with dementia }\end{array}$ \\
\hline
\end{tabular}




\begin{tabular}{|l|l|}
\hline $\begin{array}{l}\text { care, services and } \\
\text { communities. }\end{array}$ & $\begin{array}{l}\text { Increased involvement of people } \\
\text { with dementia as active co- } \\
\text { producers of policy and service } \\
\text { development }\end{array}$ \\
$\begin{array}{l}\text { Group facilitators } \\
\text { advocate for members } \\
\text { and protect against } \\
\text { tokenism' }\end{array}$ & $\begin{array}{l}\text { Better services and support for } \\
\text { people with dementia }\end{array}$ \\
$\begin{array}{l}\text { Cultural shift within the } \\
\text { health service and wider } \\
\text { commissioning arena in } \\
\text { relation to a greater } \\
\text { sense of openness and } \\
\text { interest in issues } \\
\text { affecting people with } \\
\text { dementia }\end{array}$ & \\
\hline
\end{tabular}

\section{Empowerment groups}

'Empowerment Groups' consist of people with dementia who are defined as 'members' and not service users because DNI is led by people with dementia who have agency into organizational processes rather than obtaining a service form the organization. Empowerment Groups meet monthly to provide peer support and to promote better practice in relation to dementia care. This evaluation took place during a period of expansion whereby DNI plan to set up 'Empowerment Groups' within each Health and Social Care Trust area across Northern Ireland (NI). Currently, there are five established empowerment groups geographically distributed across NI with plans to develop a further eight groups. At the time of this evaluation, DNI consisted of three staff members, five board members and 15 members with dementia. Two facilitators were recruited and selected by Dementia NI board members, one of whom had dementia and was the founding member of the organisation. Facilitators supported six empowerment groups, with one to four members per group, each with mild to moderate cognitive impairment.

CMO configurations: Having effective group facilitators (Context) who encouraged members to use existing skills and learn new skills (Mechanism) helped build members' confidence and self-esteem, along with helping them keep their minds active (Outcome).

It's about giving them (members) the opportunity to freely and openly talk, give their opinions themselves in an environment where they feel they will not be frowned upon, building their confidence and keeping their mind active (Staff Member B)

Member talked about how he had learnt new things... using mobile phone, IPad, Skype, email etc (Notes from Empowerment Group Observation)

It's about seeing what the people with dementia can do... letting them utilise all of those skills rather than taking them away. (Staff Member B) 
Empowerment groups provided a safe space for peer support (Context) where people with dementia could share experiences and learn more about dementia (Mechanism). This improved knowledge gave people with dementia the confidence to 'come out' about their illness to family and friends, which helped improve relationships, and helped reduce fears about their future with dementia (Outcome).

It (empowerment group) has helped me to understand... the journey of dementia... and I don't have the same fear (Member A)

The empowerment group is the only social space to discuss dementia. I haven't told people I have dementia. Because they would say, what is he talking about. The empowerment group helped me prepare for conversations with family and friends about my dementia (Member F)

Empowerment group membership (Context) was portrayed as creating a sense of belonging, a shared social identity, and collective strength, with members empowering each other to be open about their diagnosis (Mechanism). This change in thinking and behaviour of members helped reduce members' isolation and improved members' overall psychological wellbeing and quality of life. (Outcome)

I feel very comfortable and I enjoy the fact that you can share your problems with other people (Member A)

My mind is more at ease... they (other members) are not hiding it... they are coming out. When I had it, I didn't bother with anyone. I kept myself to myself. Never left my flat. (Member B)

Empowerment groups make it easier to speak openly... I wouldn't have worn my dementia pin if I didn't go to the empowerment groups (Member H)

The empowerment group is almost definitely stopping some of us from being depressed. It gives me a reason to live... makes me feel in control... not ashamed to tell what I think. I would be lost if this all went away. (Member F)

However, these programme mechanisms only work when people with dementia are motivated to join an empowerment group, so that the size of the group is sufficient to allow for discussion and comparison (Context).

Empowerment groups tend to attract people who are sick and tired of being brushed under the carpet (Staff Member A)

I just was sick of so many people dying... because they never admitted that they had, you know Alzheimer's that sort of thing (Member F)

Well the problem was that... I was the only member of this for a long time. I mean, (the facilitator) is great like, but there was nothing to bounce off anyone else (Member $M$ - rural area)

The stigma surrounding dementia, that the organisation and members work so hard to battle, could actually create a barrier to people with dementia actually joining the empowerment groups, especially in rural areas where the illness was still very much a 'taboo' subject (Context).

People are not coming forward because of the stigma (Member J) 
There are unique recruitment challenges in rural areas... people don't want to talk about dementia. They are very private and do not want communities knowing. (Staff Member C)

Furthermore, empowerment groups are more likely to achieve the desired outcomes when they are supported by experienced and effective facilitators (Context). For example, group facilitators were held in high esteem, and had built up trusting relationships with members, and as a result members felt motivated to take part, and enabled to see they were both worthy and capable of doing more than they thought they could post diagnosis (Mechanism).

Member talked about how without staff it (empowerment groups) wouldn't work. Another member referred to the importance of the group facilitator sharing ideas "that we wouldn't have thought of" (Notes from Observational data)

"If she wants me to do anything with her... I don't refuse it. I don't care what it is... I am glad to do it". (Member D)

When I was diagnosed, I had lost all of my confidence. I realized I had more to give. Slowly but surely I built myself up again, through hard work and other people supporting me, the staff. We need people like that (facilitator) to help build up our confidence. (Member F)

However, while empowerment groups 'worked' in terms of meeting some intended outcomes; namely improving quality of life of people with dementia, they were only able to fully achieve all intended outcomes through providing a platform for change.

It is important that we don't go down the road of support groups. That is not what we are about... if we focus on safe space and emotional support then we risk diluting what the group is about... the emotional support is a benefit... but it's an add on, it's not the purpose" (Board Member B)

It is giving people with dementia a voice... the media work has been very powerful. That didn't really happen beforehand... the media I saw before was people sitting on the sofa with their carers sitting beside them talking. And the perception was very much that that is it. You are not involved in anything., you don't have a voice.... But there wasn't that focus on what you can do with dementia the positive side, the control people do and can have. That has changed now. That is massive... because the more there is a cultural shift and societal shift, that filters through to healthcare staff." (Staff Member A)

Awareness raising

Observations, interviews and documentary analysis identified various awareness raising activities, which included improving understanding of dementia among communities, organisations and the general public. Members represented DNI through public talks, training and education (e.g. health professionals and students), information stands and through the media (radio, TV, newspapers and social media). Awareness raising also included sharing advice on how to practically support a person living with dementia or encouraging people who think they may have dementia to contact their GP. DNI provided resources to support members with dementia in awareness raising including branding, organisational skills (of staff), contacts, media training and transport to events.

CMO configuration: Awareness raising activities generated an 'activist' mentality among members, where they drew on their new found confidence, collective strength, and were motivated and driven to reduce the stigma surrounding dementia, along with highlighting the need for improving services (Mechanism). This helped increase members' psychological 
wellbeing and created a sense of satisfaction that they were making a difference to the lives of other people with dementia, along with providing greater opportunities for civic contribution and political influence at local and national level (Outcome). This required organisational and staff support in relation to providing resources and expertise for media training and other awareness raising activities (Context). Consultation was also a key enabling context in relation to providing positive feedback on awareness raising activities (Context) such as the "I'm Still Me" campaign, led by the Public Health Agency in NI, and aimed at raising awareness around the signs of dementia, along with reducing stigma and fears about the condition (http://www.publichealth.hscni.net/news/stillme-dementia-campaign-launch).

All opinions, feedback and advice of DNI members was acknowledged, used and incorporated into the campaign development process ('I'm Still Me' Media Campaign). One member of DNI featured in print advertising as part of campaign. (DNI Closing the Loop Feedback Form - Consultation with Public Health Agency)

However, interview data illustrated that the organisation provided more than simply training and resources, but also the psychological support to build members' confidence to take part in awareness raising activities. For example, some members pointed out that they would not have been able to take part in a media campaign prior to joining an empowerment group.

And other people saying... you know 'was that you on the tv'? Couldn't have done that before... cause l'd be scared to do it. They (Group Facilitator) would help me, before I do anything and say to me now 'you'll be alright. I'm there to help you'. If you find you don't want to do it, you don't have to do it. (Member O)

Members believed they were more powerful as a collective group.

We have a better chance of getting results if all people are singing from the same hymnsheet ... one voice very important". (Member $\mathrm{J}$ - Observation of Empowerment Group).

Staff also viewed empowerment groups as having an activist mentality.

There is really a lot of speculation as to what we call our groups. I like to use the word activist. I want them (members) to feel as though they have changed the face of what dementia is, and they actually are doing that". (Staff Member A)

The desire to challenge the stigma surrounding dementia was a clear theme in the data collected.

Right from day one, I said I am going forward for this and I am going to... try and be an advocate... the whole thing is lifted, that whole façade of just people hiding in their homes" (Member B)

Redressing the power balance where people with dementia where seen as passive recipients, unable to advise or make decisions in relation to their own care was also something members were clearly passionate about.

We should always be there at the decision making process, no matter where it is, across the board. We are capable of doing that and why we are not used at that level is beyond me. I'm always fighting to get involved at that decision making process because we are the people living with it... and have the most to give." (Member F)

Members alluded to improvements in their psychological wellbeing, 
It (talking at awareness raising event) was a real high" (Member D)

along with their belief that they could make a real difference for other people with dementia not just at an individual level but at a wider community/societal level.

I'm going to make it better for the next guy coming along (Member $\mathrm{L}$ )

What would be a good result? -in a years' time, or a year and a half's time, we can all say it is better now than it was two years ago - better province wide. (Member B)

While Staff felt strongly that members were the driving force behind awareness raising activities,

My work is really their (members) work...", (Staff Member C)

they also recognised that people with dementia do not necessarily have the opportunities to make a real change, and as such organisational capacity and support is crucial to raise awareness.

People with dementia do not necessarily have the opportunities. I am helping them to deliver on that (awareness raising) ... having that (people with dementia) face in the media, having somebody with dementia on the radio talking about dementia... that's really powerful for challenging and breaking down stigma. (Staff Member B)

While motivation was a key enabling context for people with dementia actually joining an empowerment group, positive feedback was also recognised as a key enabling context for maintaining that motivation among members. Without positive feedback, members could become demoralised and demotivated. (Disabling Context)

It's important they (Members) are given as much feedback as possible on how they have influenced things - to see how they are making a difference (Staff Member A)

Spoke about Chairman of health service - 'they don't want to know upstairs' (Member $\mathrm{J}$ - Observation of Empowerment Group)

\section{Consultation}

Observation, interviews, and documentary analysis also identified the wide variety of consultation activities undertaken by members. Visiting organisations, such as public health charities, health care organisations and local businesses can request to attend empowerment group meetings or send materials for feedback. Members also bring their own initiatives to the group (e.g. Dementia Friendly Communities) or will approach organisations themselves.

CMO configuration: DNI provides a forum through which people with dementia can be consulted and involved in decisions affecting their care, services and communities. This gave members a voice and built their confidence to challenge those with decision making power to listen and act on the advice and guidance provided by those actually living with dementia (Mechanism). As a result, policy makers and service providers are better informed about the needs and aspirations of people with dementia. people with dementia are actively involved in policy and service development relative to dementia, leading to better support and services (Outcome). These mechanisms and resulting outcomes are more likely to be generated in the context of empowerment groups, which help build members' confidence to speak out on issues that affect them, and provide opportunities for consultation (Context). Group facilitators advocated for members and protected against 'tokenism' by ensuring that any consultations with commissioners, practitioners, researchers and other user-led groups were followed through based on the advice and guidance provided by members (Context). Intended 
outcomes are also more likely when there is a cultural shift within the health service and wider commissioning arena in relation to a greater sense of openness and interest in issues affecting people with dementia (Context).

Evidence of member's confidence to speak out, and have a say in how services affecting them are shaped, was captured during observations of an empowerment group. Members had a very impassioned discussion about an awards event they had attended for healthcare staff who had championed issues relevant to dementia. One member expressed his frustrations that some of those who won awards had not consulted with people with dementia. This member relayed how they had approached one of the winners at the event to raise awareness of the empowerment groups which led to the winner requesting a consultation with members.

She needs to learn. She needs to see that people like us exist. (Member B)

Policy makers and service providers are better informed about the needs and aspirations of people with dementia. People with dementia are actively involved in policy and service development relative to dementia, leading to better support and services (Outcome). Evidence of how consultation activities led to improved support and services was also demonstrated in feedback from consultations with service providers.

We have fully included all feedback from the DNI members in relation to improving ongoing engagement and recording of information that is pertinent to maximising the potential prevention and management of any diagnosis of delirium. The feedback from staff questions to DNI members have been incorporated into the evaluation of the event for future reference. Engagement with the group enabled feedback in relation to language and images used to convey risks associated with delirium and how people with dementia and their family/carers can engage with healthcare staff to improve outcomes for those at risk or diagnosed with delirium. (DNI Closing the Loop Feedback Form - Consultation with Public Health Agency in relation to a Delirium Launch Event to front line staff, management and other external stakeholders)

At the initial stages of the development of the Dementia Learning and Development Framework I had arranged monthly workshops. At our very first workshop, (Member) gave a very in-depth account of her experiences of availing of health and social care (both positive and negative) throughout the three years prior to her formal diagnosis of dementia and the period thereafter. Her (Member) contribution at this very early stage set the scene and outlined the key knowledge and skills required of health and social care staff in order for them to interact and respond sensitively to the needs of those living with a dementia and their families and carers. All requests and views from DNI were accepted and incorporated into the development of the Framework. Their valuable participation and contribution recognised the importance of collaboration between the person living with dementia, their families and carers as well as health and social care staff throughout the person's journey with dementia. (DNI Closing the Loop Feedback Form - Consultation with Dementia Together NI - a public health charity)

Observation and interview data also demonstrated the importance of group facilitators for ensuring that consultation activities would bring about positive change for members, rather than simply benefiting external organisations.

Staff encourage, support and protect members - responsible for administration people who want to come in and consult with members - filters those who are genuinely wanting the opinion of people with dementia versus a tickbox exercise. (Notes from Observation of Empowerment Group) 
"Do not come and use us for your own benefit then not give feedback on how we have helped you" (Staff Member B)

For example, group facilitators developed Closing the loop documentation to ensure consultations were followed through with actions. This documentation included a Visitor Request Form where those requesting a visit to the Empowerment Group had to outline their aims and expectations for a consultation. Visitors were also requested to fill in an agreement to return a 'Closing the Loop Feedback Form' within three months of their consultation, outlining how much they, or their organisation were able to implement based on the requests and opinions of members. The increasing openness and interest in issues affecting people with dementia was evidenced by the large volume of visitor requests for consultations from those in commissioning and healthcare services, along with wider community services, such as libraries and Film theatres.

Although we have separated these three core activities, it is important to note that they are all interrelated. For example, empowerment groups are a key enabling context for awareness raising and consultation. Likewise, awareness raising and consultation are key enabling contexts for generating a sense of empowerment among members. Empowerment groups would be merely peer support groups if they did not have awareness raising and consultation as key goals.

There are various ways people can take action within the group, whether that is taking part in a discussion group, a survey, if it's indirect involvement, or very direct speaking to the media or part of a visible campaign, they are taking action to make some change and that's what is really valuable for people. Because most of them feel the action they take now will not make immediate change, but they are part of something that might make a change... the drive to want to change. It is beyond support. (Staff Member A)

Likewise, awareness raising and consultation would be less likely if members did not feel empowered to have a voice, along with opportunities for adequate training and support.

Furthermore, although we have theorised about these core activities as distinct resources offered by the organisation, we cannot fully appreciate why, and how they work without due attention to the running of the organisation as a whole. For example, observations of DNI board meetings, made up of a chairperson, a co-chairperson (member with dementia), a treasurer and two directors, provided no indication that the person with dementia was treated any differently to other members of the board. Decisions appeared to be made based on the consensus of all board members after thorough discussions. The person with dementia always referred to what do 'we' think, suggesting he felt very much involved, and put suggestions back to other members for feedback and vice versa.

The person with dementia demonstrated autonomy during the meeting, and was equally involved throughout. He was as able and comfortable to share his opinions as anyone else at the meeting. Although some members did dominate some discussions, this appeared to be more due to their personal experience in certain areas such as finance, grant bids etc. Similarly, the person with dementia more likely to dominate discussions when of more direct relevance to issues around other people with dementia. So overall, was a good mix of skill sets with everyone contributing on important issues. (Notes from Observation of DNI Board Meeting)

Furthermore, Board members were very keen to have more members involved. However, the board member with dementia recognised and pointed out that other members may not be able for, or interested in certain decision making activities.

\section{Discussion}


This evaluation used realist methods (Pawson \& Tilley, 2004) to help assess an organisation with complex processes and outcomes. This evaluation has helped shed light on how the organisation's various activities/interventions generated the intended outcomes, along with identifying what contexts facilitate/hinder the achievement of desired outcomes for people with dementia. Findings helped refine and expand our initial programme theory that Dementia NI supports the empowerment of people with dementia through a range of activities, by developing autonomy and leadership, improving inclusion, and changing perceptions of dementia, in a region where people with dementia were lacking a local voice. For example, findings revealed that DNI worked from an ethos of member-led involvement and decision making, employed effective, empathetic facilitators to set up and manage empowerment groups for and with people with dementia, provided resources and expertise for media training and other awareness raising activities, and provided a forum through which people with dementia can be consulted and involved in decisions affecting their care, services and communities (Contexts) leading to members feeling empowered and motivated to take on proactive, independent key roles within the organisation (Mechanism) which resulted in positive outcomes such as improved quality of life, improved public awareness and understanding of dementia, which may lead to reduced stigma and greater social inclusion of people with dementia, and increased involvement of people with dementia as active coproducers of policy and service development, which may again lead to better services and support for people with dementia (Outcome).

However, as our findings highlight, context is not only key at an organisational level, but also on an individual level (people with dementia are motivated to join an empowerment group), and wider HSC and policy level (real desire for change rather than tokenistic).

These findings are discussed further in relation to the critical social science literature on social power (French \& Raven, 1959) which posits that a shared social identity can engender the possibility for attitudinal and political change, while also enhancing individuals own psychological wellbeing (Clare et al., 2008). For example, findings indicated that membership of DNI created a sense of collective strength that empowered people with dementia to overcome their previous sense of isolation, social marginalisation, and overcome the challenges to self and identity caused by a diagnosis of dementia.

This process is similar to the 'virtuous circle of social identification' illustrated by Reicher and Haslam (2006), in which developing a shared social identity can lead to mutual support and therefore to successful organization. This can result in group members assuming new roles and working together to create the changes they want to see in society, through a process of collective self-realization. This in turn can lead to increased group identification and improved well-being for individual members. We can theorise that a shared social identity creates social power, creating motivation to generate the required resources, and enabling members to realise group and individual goals, resulting in political and attitudinal changes (Bruins, 1999; Turner, 2005, 2006).

Whether awareness raising and consultations will have the desired effect in terms of reducing stigma, and improving services for people with dementia remains to be seen. However, an activist mentality may have many benefits for members at an individual level in terms of feeling their lives have been enriched, and from a sense of empowerment. Although it is too soon to have any meaningful outcome measures in terms of measuring wider societal and/or cultural change, we can theorise that increased public education may influence policy changes as has been demonstrated throughout history (Hobley, 2012).

Having effective group facilitators was found to be a key enabling context for DNI empowerment groups. Although this is not a novel finding in relation to the importance of facilitation for successful implementation and sustainability of new interventions (McConnell, O'Halloran, Donnelly \& Porter, 2015), findings help provide important insights into what is the 
best mode of facilitation (Clare et al., 2008). For example, while previous research suggests that professional facilitation is crucial for groups of people with dementia due to cognitive challenges (Jones, Cheston \& Gilliard, 2002; LaBarge \& Trtanj,1995; Yale,1995), group facilitation can paradoxically foster dependence rather than independence. Our findings suggest that effective facilitation, in this context, effective in terms of enabling empowerment and independence of people with dementia, involves shared decision making, encouragement, and providing the necessary resources for people with dementia to use their many skills, and actualise their desire for involvement in key decision making processes that improve both their standing in society, and the health care that they receive.

An Innovative feature of this study was the co-production element within a realist methods approach. DNI staff and members were intricately involved in the design and analysis which helps extend our current understanding of empowerment initiatives as understood from those who are actively involved in putting empowerment into action. Our sample was made up of members with dementia, and staff who were viewed as 'working for members'. This core ethos of the organisation helped actualise the empowerment of people with dementia rather than simply pay lip service to the concept of empowerment as has been seen in previous initiatives (Miller et al, 2014). Although staff facilitated core activities/interventions, these activities/interventions were driven by members' passion about improving services and reducing the stigma surrounding dementia.

This realistic evaluation is to our knowledge the first attempt to provide insight into what works, for whom, and in what circumstances in terms of empowerment initiatives for people with dementia. These insights provide a new model for informing similar initiatives, which we urge others to test further in future research into empowering people with dementia. Within this model, we propose the following middle range theory for the successful implementation of empowerment initiatives for people with dementia.

- If people with dementia are provided with the opportunity to develop a shared social identity, this can create a sense of social power, generating motivation to access the required resources, and enabling members to realise group and individual goals, resulting in political and attitudinal changes

This middle range theory is expanded on below in light of our findings. For example, there are a number of contextual influences that make it more likely (or in some cases, less likely) that people with dementia will develop a shared social identity, and feel empowered to achieve positive outcomes at an individual, and wider political/societal level. These are outlined below.

- If group facilitators focus on encouraging members to recognise the many skills they have and can still learn, encourage shared decision making between members of the group in relation to improving services and support, provide opportunities for awareness raising and consultation with service providers and policy makers, then this is more likely to lead to improved quality of life for members, enhanced peer networks and social activity, increased confidence and self-esteem, maintenance of cognitive abilities, more openness around their diagnosis of dementia, and improved relationships with family and friends

- If the stigma surrounding dementia is not challenged, especially in rural areas where the illness is still very much a taboo subject, then expanding empowerment groups to rural areas is severely compromised as people with dementia will be more reluctant to join a group for fear of their diagnosis being exposed, preventing sufficient numbers for peer support, and collective action

- If there is organisational and staff support to set up empowerment groups, adequate resources and expertise for media training and awareness raising activities, and 
positive feedback from consultation exercises, then members will be enabled and empowered to educate the public on dementia, thereby challenging the stigma surrounding dementia, along with highlighting the need to improve services. As a result, members gain satisfaction from making a difference to the lives of people with dementia, have the opportunity for civic contribution and political influence at local and national level, and can work toward improving public awareness and understanding of dementia with the aim of reducing stigma and greater social inclusion of people with dementia

- If empowerment group facilitators generate opportunities for people with dementia to consult with policy makers, health care providers, and community services; and ensure consultations are followed up with actions based on members' advice, this empowers people with dementia to have a voice, builds their confidence to challenge those with decision making power to listen and act on the advice and guidance provided by those actually living with dementia, resulting in better informed policy makers and service providers who recognise the needs and aspirations of people with dementia, increased involvement of people with dementia as active co-producers of policy and service development, and ultimately better services and support for people with dementia.

- If there is a continuing cultural shift in the health service and wider commissioning arena in relation to a greater sense of openness and interest in issues affecting people with dementia, then they are more likely to take the advice of people with dementia on board and implement change in line with the needs of those actually living with dementia.

\section{Strengths and Limitations}

Our sample was made up of people with dementia who were willing and able to join DNI, which may introduce bias into our sample as we were unable to interview people with dementia who chose not to join. Therefore, we cannot generalise our findings to this sub-set of people with dementia. However, all staff and members who were contacted to take part participated which helps increase representativeness of our sample in relation to those who do partake in empowerment initiatives. Another limitation is our focus on only one organisation. An interesting area for further research would be the inclusion of multiple organisations with empowerment as their goal in relation to dementia. This would further expand our understanding of what works, for whom and in what circumstances, especially where organisations struggle to achieve their goals.

Although we did not uncover any negative consequences of empowerment groups, previous research has suggested that involvement can lead to fatigue (Litherland, 2015) which suggest caution in assuming only positive outcomes for members, and safeguards should be in place to ensure ongoing monitoring of members wellbeing as a code of good practice as well as an assessment of benefit.

\section{Conclusion}

These findings illuminate what works, for whom, and in what circumstances in terms of empowerment initiatives for people with dementia, and provide a new model for informing similar initiatives. Findings suggest that empowering people with dementia may be achieved through providing opportunities for people with dementia to develop a shared social identity, which can in turn generate a sense of social power. People with dementia are then motivated to access the required resources to realise group and individual goals such as creating political and attitudinal changes. This case study of DNI illustrates that there are boundaries and 
challenges to empowerment in terms of requiring additional support from staff without dementia. However, despite these challenges, empowerment driven organisations can and should be committed to involving members in lead roles and key decision-making. We urge others to test the transferability of this model in future research into empowerment initiatives for people with dementia.

\section{Acknowledgements}

We would like to express our heartfelt gratitude to staff and members of Dementia NI for giving of their time to support this research.

\section{Author contributions}

PB conceived the research, obtained funding from Disability Research on Independent Living \& Learning (DRILL) and managed all aspects of the work. MS and TS conducted all aspects of data collection. Data analysis was conducted over a number of research team and analysis meetings by MS, TS, PB, TM, NM. MD and BT provided expert advice throughout the research. TM drafted the manuscript and all authors contributed to refining the manuscript and approved the final version.

\section{Declaration of conflicting interests}

The Authors declare that there is no conflict of interest.

\section{Funding}

This work was supported by funding from Disability Research on Independent Living \& Learning (DRILL), a Programme funded by the Big Lottery Fund (Grant number FT100088).

\section{References}

Bartlett, R. (2016). Scanning the conceptual horizons of citizenship. Dementia, 15, 453-61.

Beard, R.L., Knauss, J., \& Moyer, D. (2009). Managing disability and enjoying life: How we reframe dementia through personal narratives. Journal of Aging Studies, 23, 227-235.

Bruins, J. (1999). Social power and influence tactics: A theoretical introduction. Journal of Social Issues, 55, 7-14.

Cheyne, H., Abhyankar, P., \& McCourt, C. (2013). Empowering change: Realist evaluation of a Scottish Government programme to support normal birth. Midwifery, 29, 1110-1121

Clare, L., Rowland, J., \& Quin, R. (2008). Collective strength: The impact of developing a shared social identity in early-stage dementia. Dementia, 7, 9-30.

Department of Health and Social Care (2012) Prime Minister's Challenge on Dementia delivering major improvements in dementia care and research by 2015. Retrieved from 
https://assets.publishing.service.gov.uk/government/uploads/system/uploads/attachm ent_data/file/215101/dh_133176.pdf

Department of Health and Social Care (2009) Living Well with Dementia: a national dementia strategy. Retrieved from

https://www.gov.uk/government/publications/living-well-with-dementia-a-national-dementiastrategy

Dewing, J. (2007) Participatory research: a method for process consent with persons who have dementia. Dementia: The International Journal of Social Research and Practice, $6,11-25$.

Donnelly, J. (2004). Can adults with cognitive impairment consent to take part in research. Journal of Wound Care, 13, 257-262.

Emerson, R.M., Fretz, R.I \& Shaw, L.L. (2011). Writing Ethnographic Fieldnotes. 2nd ed. Chicago, IL: University of Chicago Press.

Fereday, J., \& Muir-Cochrane, E. (2006). Demonstrating rigor using thematic analysis: A hybrid approach of inductive and deductive coding and theme development. International Journal of Qualitative Methods, 5, 80-92.

Retrieved from http://www.ualberta.ca/ iiqm/backissues/5_1/pdf/fereday.pdf.

French, J.R.P., \& Raven, B.H. (1959). The bases of social power. In D. Cartwright (Ed.), Studies in social power (pp. 150-167)

Greenhalgh, T., Humphrey, C., Hughes, J., Macfarlane, F., Butler, C., Pawson, R. (2009) How do you modernize a health service? A realist evaluation of whole-scale transformation in London. Milbank Quarterly, 87, 391-416.

Hobley M. (2012). Public opinion can play a positive role in policy making. The Guardian. Retrieved from https://www.theguardian.com/public-leadersnetwork/2012/sep/03/public-opinion-influence-policy

Jones, K., Cheston, R., \& Gilliard, J. (2002). Sharing problems through group psychotherapy. Journal of Dementia Care, 10, 26-27.

LaBarge, E., \& Trtanj, F. (1995). A support group for people in the early stages of dementia of the Alzheimer's type. Journal of Applied Gerontology, 14, 289-301

Laurier, E., \& Parr, H. (2000). Emotions and interviewing in health and disability research. Philosophy \& Geography. 3, 98-102.

Litherland, R. (2015). Developing a national user movement of people with dementia. Joseph Rowntree Foundation, York. 
Marchal, B., Dedzo, M., \& Kegels, G. (2010). A realist evaluation of the management of a wellperforming regional hospital in Ghana. BMC Health Services Research, 10, 1-24. doi: $\underline{10.1186 / 1472-6963-10-24}$

McConnell, T., O'Halloran, P., Donnelly, M., \& Porter, S. (2015). Factors affecting the successful implementation and sustainability of the Liverpool Care Pathway for dying patients: a realist evaluation BMJ Supportive and Palliative Care, 5, 70-77. doi:10.1136/bmjspcare-2014-000723

Miller, L.M., Whitlatch, C.J., \& Lyons, S.L. (2014) Shared decision-making in dementia: A review of patient and family carer involvement. Dementia, 15, 1141-1157.

O'Connor, D., Phinney, A., \& Hulko, W. (2010). Dementia at the intersections: A unique case study exploring social location. Journal of Aging Studies, 24, 30-39.

Pawson, R., \& Tilley, N. (2004) 'Realistic Evaluation' in S Matthieson (ed) Encyclopaedia of Evaluation Newbury Park: Sage

Perkins, D.D., \& Zimmerman, M.A. (1995). Empowerment theory, research and application. American Journal of Community Psychology, 23, 569-579

Prince, M., Wimo, A., Guerchet, M., Ali, G.C., Wu, Y.T., \& Prina, M. (2015). World Alzheimer's Report 2015, The Global Impact of Dementia: An analysis of prevalence, incidence, cost and trends. Alzheimer's Disease International. Retrieved from

https://www.alz.co.uk/research/WorldAlzheimerReport2015.pdf

Raeymaeckers, P., \& Dierckx, D. (2013). To work or not to work? The role of the organisational context for Social workers' perception on activation. British Journal of Social Work, 43, 1170-1189.

Rappaport, J. (1987). Terms of empowerment/exemplars of prevention: Toward a theory for community psychology. American Journal of Community Psychology, 21, 279-292.

Reicher, S., \& Haslam, S.A. (2006). Groups, psychological well-being and the health of societies. The Psychologist,19, 146-150.

Stevenson, M., \& Taylor, B.J. (2017). Involving individuals with dementia as co-researchers in analysis of findings from a qualitative study. Dementia: The International Journal of Social Research and Practice. Advance online publication. doi: 10.1177/1471301217690904

Turner, J.C. (2005). Explaining the nature of power: A three-process theory. European Journal of Social Psychology, 35, 1-22. doi: 10.1002/ejsp.244

Turner, J.C. (2006). Tyranny, freedom and social structure: Escaping our theoretical prisons. British Journal of Social Psychology,45, 41-46. 
Yale, R. (1995). Developing support groups for individuals with early stage Alzheimer's disease: Planning, implementation and evaluation. Baltimore, MD: Health Professions Press.

Varley, A. (2008). A place like this? Stories of dementia, home, and the self. Environment and Planning D: Society and Space, 26, 47-67.

Zimmerman, M. A. (1995). Psychological empowerment: Issues and illustrations. American Journal of Community Psychology, 23, 581-599 